\title{
ARE ENZYME REPLACEMENT THERAPIES EFFECTIVE AGAINST LYSOSOMAL STORAGE DISORDERS?
}

\author{
Taimoor Hassan ${ }^{1,2}$, Xu Huadong ${ }^{1}$ \\ ${ }^{1}$ School of Pharmacy \& School of Medicine, Changzhou University, Jiangsu, China, ${ }^{2}$ Department of Health \\ Professional Technologies, The University of Lahore, Pakistan
}

\begin{abstract}
Lysosomal storage disorders are an agglomeration of genetic disorders such as Fabry disease, Gaucher disease, Pompe disease, Krabbe's disease and mucopolysaccharidosis that typically impairs the prime orangs of humans, including brain, heart, musculoskeletal system, spleen, eye, and lungs. Patients with lysosomal storage disorders face mild to severe complications and even death. In order to address these health concerns, scientists are working by dint off, various therapies are introduced such as gene therapy, typical oral medicines, organ/ cell transplantation etc. However, hematopoietic stem cell transplantation and enzyme replacement therapy came out as best stakeholders to treat aforementioned disorders. Nonetheless, according to suggested data, it is concluded that presently enzyme replacement therapies are somehow ineffective for many lysosomal storage disorders till today. But we believe that in near future, as more and more research will be progressed, the ultimate therapy to these disorders will be developed.
\end{abstract}

KEYWORDS: Drug Delivery Systems; Enzyme Replacement Therapy; Fabry Disease; Lysosomal Enzyme Disorders; Lysosomal Storage Disorders; Gaucher Disease; Pompe Disease.

Cite as: Hassan T, Huadong X. Are enzyme replacement therapies effective against lysosomal storage disorders? [review article]. Gomal J Med Sci 2021 Apr-Jun; 19(2):73-7. https://doi.org/10.46903/gjms/19.02.999

\section{INTROUCTION}

Christian de Duve suggested replacing dysfunctional enzymes in lysosomal storage disorders (LSDs) with recombinant human enzymes and restoring enzymatic function in $1964 .{ }^{1}$ LSDs, as a diverse set of disorders, are linked to a plethora of genetic anomalies. These disorders are an agglomeration of 45-65 genetically acquired uncommon illnesses caused by a deficiency of lysosomal enzyme and the precocious accretion of non-degradable substrates such as carbohydrates, mucopolysaccharides, glycoproteins, glycogens and sphingolipids. Lysosomal storage of substrate poses a myriad of challenges, including metabolic imbalances, extensive physiological malfunction via cell signaling, disturbance of the lipid rafts pathway, communication impairment and cascade of mechanisms of autophagy. ${ }^{2}$ During their early childhood, the patients with LSDs have a range of clinical symptoms that might compromise

\section{Corresponding Author:}

Taimoor Hassan

Post-graduate Scholar, School of Pharmacy \&

School of Medicine,

Changzhou University, Jiangsu, China

E-mail: taimoorhassan408.th@gmail.com

$\begin{array}{ll}\text { Date Submitted: } & 05-12-2020 \\ \text { Date Revised: } & 13-03-2021 \\ \text { Date Accepted: } & 20-03-2021\end{array}$

their prime organs such as lung, heart, musculoskeletal system, eyes, spleen, liver and other organs. Furthermore, the majority of patients who have LSD's may experience austere CNS complications, and even death in their early life because of the failures in cardiorespiratory systems. ${ }^{3}$ Chemical medicines, lysosome exocytosis, enzyme replacement therapy (ERT), gene therapy and cell/ organ transplantation have all been tested as potential treatments for LSDs patients. However, hematopoietic stem cell transplantation (HSCT) and enzyme replacement therapy (ERT) are now being progressed for human trials. Owing to the complexities caused by LSDs, none of aforementioned techniques address all elements to treat these conditions. ${ }^{4}$ Having considered the efficiency and constraints of each treatment when used alone, numerous literatures have advocated the joint-venture of ERT with other therapies to address these limitations. ${ }^{5}$

\section{METHODOLOGY}

This review was conducted in School of Pharmacy \& School of Medicine, Changzhou University, Jiangsu, China from August 2020 to November 2020. In order to assess the effectivity of enzyme replacement therapies against lysosomal storage disorders, this review analyzed articles published for the period from 2012 to 2020 in both local and foreign journals. The main question of this paper was to analyze the effectivity of enzyme replacement therapies against lysosomal 
storage disorders. To answer this question, different keywords; Drug Delivery Systems, Enzyme Replacement Therapy, Fabry Disease, Lysosomal Enzyme Disorders, Lysosomal Storage Disorders, Gaucher Disease and Pompe Disease were separately and in combination searched in different electronic databases such as CINAHL, PubMed, Scopus, Web of Science, HEC digital library, and eMedicine. The article's inclusion criteria were based on the effectivity of enzyme replacement therapies against lysosomal storage disorders. Articles with copyright, irrelevant information and lacking the full text were excluded. A total of 43 articles were selected for this study, out of which in screening step, 26 articles after review of abstract, according to criteria and duplicates were removed. In last step, 17 articles were selected for the final analysis. The medium of language of all these articles was English.

\section{DISCUSSION}

Several enzyme replacement therapies have been licensed for clinical use in numerous diseases such as Krabbe, Gaucher, Pompe and Fabry diseases, and several mucopolysaccharidoses (MPSs) such as Mucopolysaccharidoses MPS I, MPS II, MPS IV, MPS $\mathrm{VI}$ as LSDs. ${ }^{5}$ BioMarin, a Pharmaceutical Company is a leading developer and commercializing agency for novel biopharmaceuticals for genetically derived rare disorders. This pharmaceutical has developed some recombinant human enzymes named Naglazyme ${ }^{\circledR}$, Vimzim $\AA$, and Aldurazyme $\AA$, for the cure of mucopolysaccharidoses (MPSs) I, II, IV and $\mathrm{VI}$ disorders. As LSDs need continual therapy for good clinical results, it is important to mention that the expense and availability to ERT should be prioritized in the treatment of such disorders. In spite of the commercial and regulative benefits of an "orphan drug" in the United States, several pharmaceutic corporations have placed LSDs therapeutic items among the costliest treatment methods in merchandise..$^{5,6}$ Unfortunately, because of being expensive, ERT (above US\$10,0000/ patient/ year) is not readily available to third world countries. Additionally, a key hurdle to the production of enzymes as medications for LSDs is the scarcity of patients in the public, which limits clinical studies. Similarly, pre-clinical investigations in lab animals are strongly advised, clinical trials in most cases have been conducted directly in human patients due to a dearth of such adequate animal model studies. ${ }^{7}$ Another significant concern of the ERT is the formation of $\mathrm{IgG}$ antibodies as an immune response against the alienated injection of enzymes that plays a significant role in the patients' protection as well as the accuracy and effectiveness of the therapy. In fact, the neutralization of antibodies can impair the effectiveness of enzyme replacement therapies by directly impairing with enzyme function as antibodies can attach to the active location of the ligand or enzyme which are involved in binding with the target cell's receptor (lysosomal integral membrane protein 2 receptors are typically responsible for Gaucher disease, likewise mannose-6-phosphate receptors are responsible for many other LSD's disorders) which specifically blocks enzymes that plays a key role in lysosomal targeting and cellular uptake. ${ }^{8}$

Likewise, the severity of immunological responses appears to be affected by the existence or lack of remaining aberrant enzymes. Genotyping for the GAA gene can predict cross-reactive immunologic materials (CRIM) in Pompe disease, and early immunomodulation can improve tolerance and result in an effective therapy. Although, the therapeutic properties of systemically given enzyme replacement therapies in contrast to LSDs, the delivery of the enzymes into affected regions of diseases (particularly the bone, CNS, heart and cornea) remains a significant obstacle. Furthermore, in MPS, the buildup of glycosaminoglycans throughout the body especially in cells and tissues causes severe systemic abnormality. MPS ophthalmological symptoms may involve both the posterior (retina, optic nerve, sclera) and anterior (conjunctiva and cornea) regions..$^{9,2}$ There is clear evidence that around $70-75 \%$ LSD patients who experience neurological abnormalities might not be employed with the existing enzyme replacement therapies. Furthermore, the blood brain barrier, is one of the key difficulties in the fight against enzyme delivery, is an impermeable hinderance between the circulation and the central nervous system that restricts the outward and inward trafficking of the enzymes which are primarily hydrophilic in nature and used as selective therapy for LSD. As a result, improving therapy responsiveness through the production of effective and safe tailored enzyme delivery systems (EDSs) might provide a potential substitute to presently employed therapies in LSDs. To address the limited entry of enzymes into challenging pathogenic locations, many strategies have been devised. ${ }^{10,11}$

Scientists have reported that the expression rate of M6PRs receptors on the targeted cells also enhances the cellular intake of enzymes through lysosomal enzyme carrier system. Presently, the development of enzyme loaded nano-systems that will deploy contemporary nanomaterials to the targeted location is expected to enhance the efficiency of enzyme replacement therapy by cutting down its possible side-effects. In order to develop nano-scaled EDS's, numerous biocompatible and biodegradable players such as nanoliposomes, nanomicelles, polymer-lipid based nanoparticles will be used. ${ }^{12}$ Encapsulated enzymes can conceal the enzyme and its physiochemical characteristics by removing some fundamental constraints of enzyme replacement therapies, such as unwanted immunologic responses and biodegradability. This can provide a meaningful protection to the 
recombinant enzymes from eliciting undesirable side effects such as uncontrolled biodistribution, increased pharmacokinetic profile by enhancing drug absorption abnormally, uncontrolled-release of enzyme supply, poor pharmacodynamics and pharmacokinetics. Furthermore, lipidic/ polymeric nanoparticles coated with homing agents (such as antibodies and aptamers) can be employed to pass physiological barriers such as blood-brainbarrier (BBB) and blood-ocular-barrier (BOB)..$^{13}$ As a result, they are regarded as novel and successful techniques for the treatment of brain illnesses. Furthermore, encapsulated-cell therapy also known as (ECT) in combination with other therapeutic strategies is strongly proposed as an intriguing joint-venture therapy method for the management of various lysosomal disorders. A promising advantage of ECT is its ability to encapsulate biotechnologically engineered cells with active biocompatible devices that infix these cells to various parts of humans surgically, and more typically in those areas of human body where approach is quite difficult such as eye and brain for a longer period of time to get maximum results. ${ }^{14}$ Because of the effective blockades supplied by both endothelial and epithelial cells in the eye, tailored medication administration employing modern technology and devices may produce excellent therapeutic effects. ${ }^{14}$ Thermo-responsive sol-gel injectable hydrogels, have a wide range of potential use in administration of drug, tissue engineering and cellular treatment. It is a point of emphasis that many of aforementioned technologies have largely been employed in their respective pre-clinical trials and human clinical trials are requiring approbation of their longer safety and therapeutic effects. ${ }^{15}$ Based on collected data from all these studies, it is concluded that presently ERT's are somehow ineffective for many lysosomal storage disorders till today. But we believe that in near future, as more and more research will be progressed, the ultimate therapy for LSD's will be based on either cellular or gene therapy. ${ }^{1,7}$

In Krabbe disease, a gene therapy named AAVrh10 is reported to be an effective therapy for peripheral and central nervous systems in mouse and other animal models. At this moment, probably the most difficult hurdle in the management of LSDs is delivering therapeutic chemicals to aberrant parts such as in tissues and cells by utilizing nano-scaled enzyme delivery systems (EDSs). Multimodal nanomedicines have already been developed to treat various LSD's. ${ }^{16}$ We also know that morphology and size of nano systems (NSs) can affect the pharmacokinetic and ultimate destiny of drug delivery molecules. ${ }^{6}$ It is also a point of discussion that while taking about the enzyme delivery systems, its active and passive targeting mechanisms should be considered clearly depending upon its biological targets and implications on ERT's. A key problem in this domain is the development of tailored NSs for the delivery of enzymes to central nervous system and other tissues where approach is quite sensitive and difficult. ${ }^{10}$

Table 1: FDA approved enzyme replacement therapies for lysosomal storage disorders (LDS's)

\begin{tabular}{|c|c|c|c|c|}
\hline LDSs & $\begin{array}{l}\text { Deficient Enzyme } \\
\text { name }\end{array}$ & Inheritance & FDA approved therapies & Citation \\
\hline Fabry disease & a-galactosidase & X-linked & $\begin{array}{l}\text { Agalsidase } \beta\left(\text { Replagal }^{\mathrm{TM}}\right) / \text { 2003-FDA, EMA } \\
\text { Agalsidase a }\left(\text { Fabrazyme }^{\mathrm{TM}}\right) / \text { 2001-EMA }\end{array}$ & 2 \\
\hline Gaucher disease & $\beta$-glucocerebrosidase & Autosomal & $\begin{array}{l}\text { Taliglucerase }\left(\text { Elelyso }^{\mathrm{TM}}\right) / \text { 2012-FDA } \\
\text { Velaglucerase }\left(\text { VPRIV }^{\mathrm{TM}}\right) / 2 \text { 2010-FDA, EMA } \\
\text { Imiglucerase }\left(\text { Cerezyme }^{\mathrm{TM}}\right) / \text { 1994-FDA; 1997-EMA } \\
\text { Aglucerase }\left(\text { Ceredase }^{\mathrm{TM}}\right) / \text { 1991-FDA }\end{array}$ & 5 \\
\hline $\begin{array}{l}\text { Lysosomal acid } \\
\text { lipase deficiency }\end{array}$ & Lysosomal acid lipase & Autosomal & Sebelipase a $\left(\right.$ Kanuma $\left.^{\mathrm{TM}}\right) /$ 2015-FDA, EMA & 3 \\
\hline Pompe disease & a-glucosidase & Autosomal & $\begin{array}{l}\text { Aglucosidase }\left(\text { Lumizyme }^{\mathrm{TM}}\right) / \text { 2010-FDA, } \\
\text { Aglucosidase }\left(\text { (Myozyme }^{\mathrm{TM}} \text { )/ 2006-FDA, EMA }\right.\end{array}$ & 3 \\
\hline $\begin{array}{l}\text { MPS I } \\
\text { (Hurler syn.) }\end{array}$ & a-L-iduronidase & Autosomal & Laronidase (Aldurazyme ${ }^{\mathrm{TM}}$ )/ 2003-FDA, EMA & 6 \\
\hline $\begin{array}{l}\text { MPS II } \\
\text { (Hunter syn.) }\end{array}$ & Iduronate sulfatase $\mathrm{N}$ - & X-linked & Idursulfase $\left(\right.$ Elaprase $\left.^{\mathrm{TM}}\right) / 2006-F D A ; 2007-E M A$ & 6 \\
\hline $\begin{array}{l}\text { MPS IV A } \\
\text { (Morquio A syn.) }\end{array}$ & $\begin{array}{l}\text { Acetylgalactosamine } \\
6 \text {-sulfatase N- }\end{array}$ & Autosomal & Elosulfase Alfa $\left(\right.$ Vimzim $\left.^{\mathrm{TM}}\right) /$ 2014-FDA & 6 \\
\hline $\begin{array}{l}\text { MPS VI (Mara- } \\
\text { teaux-Lamy syn.) }\end{array}$ & $\begin{array}{l}\text { Acetylgalactosamine } \\
\text { 4-sulfatase }\end{array}$ & Autosomal & Galsulfase $\left(\right.$ Naglazyme $\left.{ }^{\mathrm{TM}}\right) /$ 2005-FDA; 2006-EMA & 6 \\
\hline
\end{tabular}


Vesicular trafficking mechanisms in LSDs (such as membranous caveolae and clathrin-coated pits) must also be thoroughly investigated. Lysosomal compartments include about 55 membrane proteins, 65 distinct types of hydrolases enzymes, and other agents that are involved in biological entity breakdown. Still, we need to clearly understand the holistic function of lysosomal membrane transporters in lysosomal movement. ${ }^{17}$ The interdigitation of lysosomal divisions with other components of the cells appear to be heavily reliant on the activities of lysosomal transporters and ion channels, any abnormality in these channels and transporters may contribute to the pathogenesis of lysosomal storage disorders. But we still don't know what role lipid rafts and other cytoplasmic entities such as coat proteins play in vesicular movement. Similarly, in order to cure LSDs, a variety of challenges concerning the epigenetics/ genetics of the lysosomal divisions must be addressed..$^{13}$ Overall, it is a time to alter our research focus from a restricted concentration to a broader viewpoint. To achieve this aim, we must first understand the characteristics of lysosomal storage disorders, as well as their clinical and biochemical properties, in order to deliver more effective therapy to patients. The development of nano-scaled tailored therapies against LSDs appears to be a foregone conclusion in this domain. (Table 1)

\section{REFERENCES}

1. Whyte MP, Greenberg CR, Salman NJ, Bober MB, McAlister WH, Wenkert D, et al. Enzyme-replacement therapy in life-threatening hypophosphatasia. N Engl J Med 2012 Mar 8;366(10):904-13. https://doi.org/10.1056/NEJMoa1106173

2. Germain DP, Elliott PM, Falissard B, Fomin VV, Hilz MJ, Jovanovic A, et al. The effect of enzyme replacement therapy on clinical outcomes in male patients with Fabry disease: A systematic literature review by a European panel of experts. Mol Genet Metab 2019 Jun 1; 19:100454. https:// doi.org/10.1016/j.ymgmr.2019.100454

3. Li M. Enzyme replacement therapy: a review and its role in treating lysosomal storage diseases. Pediatr Ann 2018 May 1;47(5): e191-7. https:// doi.org/10.3928/19382359-20180424-01

4. Parini R, De Lorenzo P, Dardis A, Burlina A, Cassio $A$, Cavarzere $P$, et al. Long term clinical history of an Italian cohort of infantile onset Pompe disease treated with enzyme replacement therapy. Orphanet J Rare Dis 2018 Dec;13(1):1-2. https:// doi.org/10.1186/s13023-018-0771-0

5. van der Ploeg AT, Kruijshaar ME, Toscano A, Laforêt $\mathrm{P}$, Angelini $\mathrm{C}$, Lachmann $\mathrm{RH}$, et al. European consensus for starting and stopping enzyme replacement therapy in adult patients with Pompe disease: a 10-year experience. Eur J Neurol 2017 Jun;24(6):768-e31. https://doi. org/10.1111/ene.13285
6. Parini R, Deodato F. Intravenous enzyme replacement therapy in mucopolysaccharidoses: clinical effectiveness and limitations. Int J Mol Sci 2020 Jan;21 (8):2975-84. https://doi.org/10.3390/ ijms21082975

7. Meena NK, Ralston E, Raben N, Puertollano R. Enzyme replacement therapy can reverse pathogenic cascade in Pompe disease. Mol. Ther Methods Clin Dev 2020 Sep 11;18(5):199-214. https://doi.org/10.1016/j.omtm.2020.05.026

8. Julien DC, Woolgar K, Pollard L, Miller H, Desai $A$, Lindstrom $K$, et al. Immune modulation for enzyme replacement therapy in a female patient with Hunter syndrome. Front immunol. 2020 May 21;11(7):1000-09. https://doi.org/10.3389/ fimmu.2020.01000

9. Solano ML, Fainboim A, Politei J, Porras-Hurtado GL, Martins AM, Souza CF, et al. Enzyme replacement therapy interruption in patients with Mucopolysaccharidoses: recommendations for distinct scenarios in Latin America. Mol Genet Metab 2020 Jun 1; 23(7):1005-22. https://doi. org/10.1016/j.ymgmr.2020.100572

10. Sato Y, Okuyama T. Novel enzyme replacement therapies for neuropathic mucopolysaccharidoses. Int J Mol Sci 2020 Jan;21 (2):400. https://doi. org/10.3390/ijms21020400

11. El Dib R, Gomaa H, Ortiz A, Politei J, Kapoor A, Barreto F. Enzyme replacement therapy for Anderson-Fabry disease: A complementary overview of a Cochrane publication through a linear regression and a pooled analysis of proportions from cohort studies. PloS One 2017 Mar 15;12(3):e0173358. https://doi.org/10.1371/ journal.pone.0173358

12. Joanne M, Skye N, Tracy M. The effectiveness of enzyme replacement therapy for juvenile-onset Pompe disease: A systematic review. J Inherit Metab Dis 2019 Jan;42(1):57-65. https://doi. org/10.1002/jimd.12027

13. Kim DH, Lee HS, Kwon TW, Han YM, Kang NW, Lee MY, et al. Single enzyme nanoparticle, an effective tool for enzyme replacement therapy. Arch Pharm Res 2020 Jan;43(1):1-21. https://doi. org/10.1007/s12272-020-01216-3

14. Madsen CV, Granqvist H, Petersen JH, Rasmussen ÅK, Lund AM, Oturai P, et al. Age-related renal function decline in Fabry disease patients on enzyme replacement therapy: a longitudinal cohort study. Nephrol Dial Transplant 2019 Sep 1;34(9):1525-33. https://doi.org/10.1093/ndt/ gfy357

15. van Kooten HA, Harlaar L, van der Beek NA, van Doorn PA, van der Ploeg AT, Brusse E, et al. Discontinuation of enzyme replacement therapy in adults with Pompe disease: Evaluating the European Pompe Consortium stop criteria. J Neuromuscul Dis 2020 Jan 1;30(1):59-66. https:// doi.org/10.1016/j.nmd.2019.11.007 
16. Limgala RP, Goker-Alpan O. Effect of substrate reduction therapy in comparison to enzyme replacement therapy on immune aspects and bone involvement in Gaucher disease. Biomolecules 2020 Apr;10(4):526. https://doi.org/10.3390/ biom10040526
17. Zhuang J, Duan Y, Zhang Q, Gao W, Li S, Fang $\mathrm{RH}$, et al. Multimodal enzyme delivery and therapy enabled by cell membrane-coated metal-organic framework nanoparticles. Nano Lett $2020 \mathrm{Apr}$ 30;20(5):4051-8. https://doi.org/10.1021/acs. nanolett.0c01654

\section{AUTHORS' CONTRIBUTION}

The following authors have made substantial contributions to the manuscript as under:
Conception or Design:
$\mathrm{TH}, \mathrm{XH}$
Acquisition, Analysis or Interpretation of Data:
$\mathrm{TH}, \mathrm{XH}$
Manuscript Writing \& Approval:
$\mathrm{TH}, \mathrm{XH}$

All the authors agree to be accountable for all aspects of the work in ensuring that questions related to the accuracy or integrity of any part of the work are appropriately investigated and resolved.

Copyright (C) 2021. Taimoor Hassan, et al. This is an Open Access article distributed under the terms
of the Creative Commons Attribution-NonCommercial 4.0 International License, which permits unre-
stricted use, distribution \& reproduction in any medium provided that original work is cited properly.

